\title{
The Role of Science Centres and Planetaria
}

\author{
Nick Lomb \\ Sydney Observatory/Powerhouse Museum \\ PO Box K346, Haymarket, NSW 1238 Australia \\ E-mail: nickl@phm.gov.au
}

\section{Introduction}

The school curriculum in many countries includes astronomical topics such as the seasons, phases of the moon, planets and stars. Yet most teachers at all school levels do not know any astronomy and have difficulty teaching that part of the curriculum. Even if they have some knowledge of the subject they may not have the resources to illustrate it and enthuse their students. One solution is to take them to a place specializing in astronomy education - a suitable science center or museum or planetarium or public observatory.

\section{What are science centers and planetariums?}

These are places that are dedicated to illustrating and explaining astronomical concepts. There are different types of institutions, though some have elements of more than one:

- Science centers have interactive or 'hands on' exhibits. They cover a variety of scientific subjects that in some cases include astronomy.

- Planetariums project star fields and astronomical images on a curved dome above an audience.

- Museums have objects and displays. Like science centers they cover a variety of subjects that in some cases include astronomy.

- Public observatories have telescopes that are available to the public.

\section{Why take students to a science center or planetarium?}

Teachers take their students to science centers, planetariums or similar places for a variety of reasons:

- Students can be instructed by someone knowledgeable about astronomy.

- Students will be stimulated by the exhibits, the show, the ambiance.

- Students will enjoy the experience. 
However, teachers may face a number of negative considerations that hinder them from going to these places:

- It could be expensive to reach the science center. For example, it may be necessary to hire a bus.

- Teachers of other subjects may not want the students to miss their classes and so may oppose long excursions.

- An evening visit to a public observatory is out of normal working hours for teachers.

- Students may ask questions after a visit that the teacher may not be able to answer. This is a situation a teacher may find embarrassing and so may want to avoid.

The Powerhouse Museum has found that links to school curriculum are not always reason for an excursion, but they are important for the teacher to justify it. Teachers consider that a visit must meet not only academic goals, but social, cultural and vocational ones as well. They value the opportunity of experiential learning for their students in contrast to the normal verbal experience of the classroom yet at the same time they want them 'to see something real'.

\section{What do students want at a science center or planetarium?}

The Powerhouse Museum recently completed a 'front end evaluation' for a new Space Exhibition. The evaluation took the form of a series of representative members of the public being invited to discuss their attitudes to the subject in small groups. These 'focus groups' were conducted for the Museum by a market research company, Stollznow Research. One group was made up of 14 to 15 year old lower secondary students. Some results from that group were as follows:

- The students were only interested in what directly involves them. For example they were interested in what it is like living in space, but only because they thought that they may have the opportunity to go there in the future.

- They want exhibits with interaction and still more interaction.

- They would like exhibits that allow them to experience weightlessness (rather difficult to provide!), go in a spacecraft, etc.

- The best exhibit that the students had experienced was where they could ride a bike and see how fast they had to ride to make something work such as a hair dryer.

\section{What happens during a visit to a science center or planetarium?}

Sydney Observatory provides a good example of a visit to a science center or planetarium. It is the oldest existing observatory in Australia and is now, as part 
of the Powerhouse Museum, a museum of astronomy and a public observatory. It has over 80,000 visitors a year, of which around 20,000 are school students. It has displays of historic astronomical instruments, modern interactive exhibits, a small planetarium and a $3 \mathrm{D}$ theater.

School visits are highly structured with the students divided into groups of 15 or so, each accompanied by a guide-lecturer. During the one and a half hour visit the guide-lecturer concentrates on the topic, such as the solar system or the nature of stars, requested by the teacher in advance.

During the visit a variety of experiences are provided to the students. They can look through the two large telescopes in the building at the Sun (with appropriate filters) or at a star if it is clear or something near the horizon if it is cloudy. They visit the exhibition, especially the section on the solar system as that is generally requested by primary teachers. They also visit the small planetarium and the 3D theater where they wear polarized glasses to go on a trip to Mars or a journey around the solar system. Most important of all during their visit to Sydney Observatory they have the opportunity to interact with a guide-lecturer and to ask him or her lots of questions.

\section{Discussion}

Science centers, planetariums, museums and public observatories provide the interaction and variety of experiences that both teachers and students value on school excursions. They assist teachers who may not be fully knowledgeable about astronomy to communicate the subject to their students.

Museums (science centers, planetariums), however, are not efficient places for traditional 'school-type' education, that is, for learning specific facts and concepts. The students do not spend enough time on an excursion for that purpose and are usually too excited to be in a receptive state of mind. Instead, museums and planetariums are ideal places for providing wonder, for the opportunity of exploring a variety of concepts and for expanding young minds.

Acknowledgments. I would like to acknowledge valuable discussions with my colleagues from Sydney Observatory, Toner Stevenson and Jeanie Kitchener. The Powerhouse Museum experience on learning during school excursions is taken from the work of Helen Whitty of the Museum's Education and Visitor Services and the work of the Museum's Evaluation and Visitor Research Unit led by Carol Scott.

\section{References}

Whitty, Helen 1999, "Making a school excursion a learning experience: A work in progress", presented at "Musing on Learning" seminar, Australian Museum 